\title{
The Dark Side of the Moon - the Side Effects of Therapy in a Dynamic Era of Breast Cancer Management
}

\author{
Richard Greil \\ Universitätsklinik für Innere Medizin III mit Hämatologie, internistische Onkologie, Hämostaseologie, Infektiologie und Rheumatologie, \\ Onkologisches Zentrum, Paracelsus Medizinische Privatuniversität Salzburg, Austria
}

In this issue of BREAST CARE a number of articles shed light on the side effects of therapies in the treatment of breast cancer. This is an important issue in the decision-making processes aiming at a fair tradeoff between benefit and risk for the individual patient. In its essence this merging of knowledge of evidence based medicine from the literature, the oncologists' personal experience with specific comorbidities and the problems of the individual patient is at the very heart of medicine. The quality of treatment decisions is the core of the art of oncology and must be steadily adapted to the development of the field. This is true for any type of cancer but the following factors stress the importance for resetting considerations in treatment decisions and research orientation in breast cancer:

The prognosis of breast cancer patients is continuously improving, with an increasing number of long-term survivors in early stages of disease [1-3]. This means that in an ageing population with a constant increase in life expectancy of 3 months per year since the 1840 s $[4,5]$ more women than ever before will survive [2] long enough to experience long-term complications. This is the price which has to be paid for the rapid and substantial progress, a phenomenon which has previously turned out to be of paradigmatic relevance in Hodgkin's disease $[6,7]$ and some tumors of childhood and early adulthood [8].

In addition, breast cancer is now understood as a primarily systemic disease from its early onset. This is underlined by the observation that micrometastases in bone marrow [9] and circulating cytokeratin-positive peripheral blood cells [10] occur early during disease and may be of prognostic impact. The lack of a plateau in relapse-free survival curves of breast cancer patients substantiates the chronic nature of this disease $[11,12]$. As a consequence of earlier diagnosis often associated with initial presence of micrometatases, of improved treatment results, and the prolongation of the natural life expectancy, more women will be candidates for (neo)adjuvant treatment and an increasing number of rescue regimens in relapse. Therefore, women with breast cancer will live a longer period of life under and after treatment and have to expect a higher number and cumulative dosages of drugs they will be exposed to. In consequence, the life time prone to side effects or complications will increase.

Simultaneously, the treatment of early stages of breast cancer is becoming increasingly aggressive, with prolongation of adjuvant antihormonal therapies beyond 5 and probably 10 years at least in lymph node positive hormone receptor positive patients $[13,14]$. This is also true for the chemotherapy regimens used in the neaodjuvant as well as the adjuvant setting. Dose-dense [15] and dose-intense chemotherapy regimens are increasingly used. This is true for patients in the US who traditionally receive therapies based on cytotoxic agents as well as in Europe which is characterized by a higher trend towards antihormonal therapy [16].

In the metastatic setting a growing percentage of patients has previously received anthracyclines and/or taxanes in the (neo)adjuvant setting. Since these drugs are the currently most effective cyctoxics also in advanced stages, their use as single agents and/or backbone of combination regimens remains without comparable alternatives in many instances. This may cause a higher propensity towards cardiac, neurological and mucoepidermal complications even when the drugs are captured in nanoparticle shelfs, such as lipids, or bound to albumin. At least the avoidance of cardiotoxicity [17] will more frequently be at the price of mucocutaneous [18] or hematopoietic side effects. This choice between 'Scylla and Charybdis' may be exaggerated in the future by the successful use of drugs targeting the Her2 signaling pathways early during treatment $[19,20]$ or by drugs targeting the epidermal growth factor receptor pathway [21].

It seems reasonable [22] that the prognosis of cancer in general and of breast cancer in particular is related to the total

\section{KARGER}

Fax +497614520714

Information@Karger.de

www.karger.com (c) 2009 S. Karger GmbH, Freiburg

Accessible online at:

www.karger.com/brc 
number of drugs available [23]; probably more than to the efficiency of a certain single drug or a multidrug regimen used in first line. The Karolinska report [24] demonstrates that the early uptake of novel drugs by the market is directly associated with outcome benefits in the cancer population. In consequence, the rational interpretation of these findings is that fortunately many patients will receive most or all of the effective and novel drugs for their specific type of cancer. Many of the future drugs applied during the further course of the disease will be unknown at the time treatment is started. This means that the arsenal of drugs applicable during the patient's lifetime but also the range of side effects tolerable in type and severity have to be considered or anticipated and respected in advance.

Clinical trials are recognized as benchmark for quality control, based on the results from a Cochrane meta-analysis demonstrating a better outcome for patients in trials [25]. The building of cancer centers and breast units correctly mandates a high percentage of patients to be included in trials. The dark side of the shining moon of scientific and clinical advancement, however, may consist in the pressure of patients, physicians, and pharmaceutical industry towards a very rapid progression from the first-in-man dose to marketing of drugs and a shortening of the very expensive clinical development program of drugs, e.g. by recently launched 'phase 0 ' trials [26-28]. The rush into the transfer of data from patients with metastatic breast cancer to earlier stages of disease is also a two-edged sword. The neoadjuvant approach is promising in many regards but the uncritical use of pathological complete response (pCR) as a surrogate marker for improved outcome may foster ever more aggressive preoperative therapies thus increasing long-term side effects which go unrecognized since these trials are usually closed after surgery and long-term follow-up is the exception rather than the rule [29]. In the adjuvant situation, the follow-up time usually is also restricted due to the high costs associated.

In trials cancer drugs are tested in patients with a very restricted comorbidity profile. The interaction of anticancer drugs in a more real-life scenario where patients may suffer from a substantial number of comorbidities requiring further medication, does not only mean a higher vulnerability and a lower threshold for organ damage, but also translates into an unforeseeable toxicity profile. As a consequence, the results from long-term postmarketing studies may substantially alter the estimation of risk/benefit ratios. For example the number needed to treat (NNT) in order to save one life within 3 years after treatment with trastuzumab is considered to be 1:40, and the NNT for a 3-year disease-free survival (DFS) advantage 1:8. This has to be balanced against a number needed to harm (NNH) in terms of a New York Heart Association (NYHA) class 3,4 or 5 event of 1:30 and a risk for symptomatic or asymptomatic cardiac dysfunction of 1:5. Apparently, these data were recorded from extremely selected patients well controlled in trials and the current view of the scientific community for a positive benefit/risk balance for trastuzumab is well taken. However, this view needs careful adaptation, particularly in very low-risk patients, in whom the relative risk reduction results in a very small absolute benefit, and in patients with unrecognized or subclinical cardiovascular problems.

\section{What Are the Novel Challenges from these Develop- ments?}

With the better understanding of signal transduction processes in cancer cells and its use for tailoring molecular or genetic factors for response prediction and target identification, more patients will receive drugs targeting a narrow spectrum of pro-survival pathways in specific cancer cells. This likely will translate into synergy in toxicity profiles of tailored drug combinations. For example, women with triple negative breast cancer will increasingly receive platinum/taxane combinations $[30,31]$ and as a result, severe polyneuropathy will emerge as a novel problem in breast cancer therapy [32]. Currently, platinum-based neuropathy is more often recognized as an irreversible or long-term complication in a substantial proportion of colon cancer patients surviving locally advanced disease. Unfortunately, the benefits of currently recommended preventive and therapeutic approaches are overestimated and modest at best.

Asthenia and fatigue emerge as relevant side effects of docetaxel-based regimens, particularly in the metastatic setting. Little effort is directed towards the understanding of the pathophysiologic principles underlying these side effects and they are often underestimated in terms of clinical relevance as compared to the traditional danger signal neutropenia. Fatigue is often attributed to anemia, but in patients with hemoglobin levels above $10 \mathrm{~g} / \mathrm{dl}$ less than $20 \%$ of the fatigue problem can be attributed to this moderate anemia [33].

Neurocognitive side effects of cytotoxic and antihormonal therapies are beginning to be a matter of concern. However, despite the increasing evidence for unexpected side effects of hormonal replacement therapy like dementia and increased cardiovascular events, data on the effects of antihormonal therapy on neurocognitive functions are sparse and controversial $[34,35]$. It is, however, laudable that studies on the pathophysiology of neurocognitive side effects of cytotoxics [36] have been started [37].

Since the so called 'biologicals' used for 'targeted therapies' are often characterized by a low or modest degree of efficacy by their own, the trend for multikinase inhibitors or combinations of drugs acting within the same biologic process, such as neoangiogenesis, are of interest. Despite hints for increasing the efficacy by such approaches, unexpected and substantial increases in severe cardiovascular toxicity, microangiopathic hemolysis and thrombotic thrombocytopenic prupura are observed when for example combining bevacizumab with sunitinib [38]. It also has to be recognized that vascular endothelial growth factor has substantial consequences for neurogenesis 
and cognitive functions in rats [39], and that the current observations guarantee safety in this regard only for patients with metastatic disease and a rather short life expectancy.

\section{Problem Solutions}

Cancer research and the care for breast cancer patients must be more tightly linked to each other. Oncologists are primarily focused on fighting cancer and so is the pipeline orientation of pharmaceutical companies. For other disciplines however, the traditional research hotspots are outside of organ specific side effects of anticancer drugs. Only the understanding of breast cancer treatment as the care for patients in a multidimensional approach covering physical, psychological and social consequences of the disease and not an exclusive concentration on the shrinkage of tumors guarantee the adequate recognition of short- and long-term side effects of cancer therapy. This approach, however, is not sufficient to establish and foster necessary research. Basic research must be driven much more by clinical needs.

It is necessary to avoid euphemistic misuse of terms for characterizing novel drugs. Neither efficacy nor tolerability will be improved by the broad usage of the term 'targeted therapy' for drugs which sometimes essentially rely on off-target effects. Classical cytotxic therapies are sometimes clearly more targeted than 'targeted therapies', and 'targeted therapies' or 'biologicals' are not per se less dangerous than cytotoxic therapies. In many instances, only less is known about the side effects. Oncologists should not become the victims of simple advertising by pharmaceutical companies or betrayed by their own uncritical view of the media. They should not forget to critically look for novel or unexpected side effects.

The observation of osteonecrosis of the jaw, which was only recognized in post-marketing studies after thousands of patients had been included in trials of bisphosphonates without such observations made, underlines the problems of current trial designs for side effect recognition. This might be even more true for modern drugs, such as antiangiogenetic agents. An essential paradigm for the conversion of hopes into frustration and concern might be the long-term and broad use of erythropoiesis stimulating agents [40]. The problem is even more severe for investigator initiated trials even when performed by well renowned cooperative study groups, since their documentation of toxicity and side effects is of worse quality than in approval trials. Long-term observations of trials and registers for toxicities should be made mandatory by regulatory agencies and be supported by governmental and pharmaceutical sponsorships.

Establishment of biobanks should not only be motivated by the insight into tumor biochemistry and biology that might be gained but also by the understanding that they provide essential tools for defining genetic polymorphisms predisposing to certain acute and long-term toxicities of drugs. Tailoring individualized breast cancer therapies could thereby be empowered for optimization of efficacy as well as toxicity profiles. Networks for genetic efforts in drug toxicity programs have recently been established, e.g. by the Serious Adverse Event Consortium, the Warfarin Consortium, and the European Collaboration for Studying the Genetic Basis of Adverse Drug Reaction Programs [41], but the author is not aware of such large-scale programs in oncology. They certainly would be worth considering.

The currently available tools for determination of quality of life were an important step for understanding and accepting quality of life as a topic amenable to research. However, more recently significant problems arose with these tools. They seem to be unable to correlate and interpret differences in objective side effects with differences in the patients' perception of quality of life. They are not specific enough to discern the effect of the addition of 'biologicals' to cytotoxics. This may be a particular problem in patients with breast cancer, who are often asymptomatic and in a good performance status even in the metastatic stage of their disease. In such scenarios, the quality of life profile may be driven by the basic cytotoxic rather than by differences in the drugs added. This makes it difficult to weigh modest improvements in cancer-specific outcome and quality of life against costs. In addition, quality of life instruments are not adapted to long-term analyses and patitents' acceptance declines within short periods of treatment. Adequate benefit/risk estimations, however, will increasingly require the tradeoff between short- and long-term quality of life estimations. We definitely need much more progress in research on quality of life and adequate tools for its measurement to justify incorporation of such data in consultation of patients and refinement of the decision-making process.

In summary, with always better results in terms of tumor control, a closer and more scientific look at the development of side effect profiles of breast cancer treatment is mandated. More and more the benefit/side effect ratio acceptable for an individual patient will be driven by the categorization of lifetime risks similar to the cancer types for which breakthroughs have been observed long ago. This requires new and exciting scientific programs in search for genetic predispositions towards side effects, larger population-based registries for adequate long-term follow-up within and outside of clinical trials, a careful avoidance of euphemistic labeling of novel drugs and a change in the communication between physicians and patients. Indeed, the discussion of long-term effects of drugs and of yet unproven but plausible or possible side effects will become a more important part of the patient-physician relationship in the future. 


\section{References}

1 Ganz PA, Hahn EE: Implementing a survivorship care plan for patients with breast cancer. J Clin Oncol 2008;26:759-767.

$\checkmark 2$ De Angelis R, Tavilla A, Verdecchia A, Scoppa S, Hachey M, Feuer EJ, Mariotto AB: Breast cancer survivors in the united states: geographic variability and time trends, 2005-2015. Cancer 2009;115:1954-1966.

$\checkmark 3$ Verdecchia A, Guzzinati S, Francisci S, De Angelis R, Bray F, Allemani C, Tavilla A, Santaquilani M, Sant M: Survival trends in european cancer patients diagnosed from 1988 to 1999. Eur J Cancer 2009;45: 1042-1066.

4 Oeppen J, Vaupel J: Broken limits to life expectancy. Science 2002;296:1029-1031.

5 United Nations Department of Economic and Social Affairs PDWPPTR: 2005.

6 Diehl V, Stein H, Hummel M, Zollinger R, Connors JM: Hodgkin's lymphoma: Biology and treatmen strategies for primary, refractory, and relapsed disease. Hematology Am Soc Hematol Educ Program 2003:225-247.

7 Diehl V, Thomas RK, Re D: Part ii: Hodgkin's lymphoma--diagnosis and treatment. Lancet Oncol 2004; 5:19-26.

8 Landier W, Bhatia S: Cancer survivorship: a pediatric perspective. Oncologist 2008;13:1181-1192.

$\checkmark 9$ Braun S, Vogl FD, Naume B, Janni W, Osborne MP, Coombes RC, Schlimok G, Diel IJ, Gerber B Gebauer G, Pierga JY, Marth C, Oruzio D, Wiedswang G, Solomayer EF, Kundt G, Strobl B, Fehm T, Wong GY, Bliss J, Vincent-Salomon A, Pantel K: A pooled analysis of bone marrow micrometastasis in breast cancer. N Engl J Med 2005;353:793-802.

10 Xenidis N, Ignatiadis M, Apostolaki S, Perraki M, Kalbakis K, Agelaki S, Stathopoulos EN, Chlouverakis G, Lianidou E, Kakolyris S, Georgoulias V, Mavroudis D: Cytokeratin-19 mRNA-positive circulating tumor cells after adjuvant chemotherapy in patients with early breast cancer. J Clin Oncol 2009; 27:2177-2184

11 Berube S, Provencher L, Robert J, Jacob S, Hebert-Croteau N, Lemieux J, Duchesne T, Brisson $\mathrm{J}$ : Quantitative exploration of possible reasons for the recent improvement in breast cancer survival. Breast Cancer Res Treat 2007;106:419-431.

12 Effects of chemotherapy and hormonal therapy for early breast cancer on recurrence and 15 -year survival: An overview of the randomised trials. Lancet 2005;365:1687-1717.

13 Goss PE, Ingle JN, Martino S, Robert NJ, Muss HB, Piccart MJ, Castiglione M, Tu D, Shepherd LE, Pritchard KI, Livingston RB, Davidson NE, Norton L, Perez EA, Abrams JS, Therasse P, Palmer MJ, Pater JL: A randomized trial of letrozole in postmenopausal women after five years of tamoxifen therapy for early-stage breast cancer. N Engl J Med 2003;349:1793-1802.

14 Goss PE, Muss HB, Ingle JN, Whelan TJ, Wu M: Extended adjuvant endocrine therapy in breast cancer: current status and future directions. Clin Breast Cancer 2008;8:411-417.

$\checkmark 15$ Citron ML, Berry DA, Cirrincione C, Hudis C, Winer EP, Gradishar WJ, Davidson NE, Martino S, Livingston R, Ingle JN, Perez EA, Carpenter J, Hurd D, Holland JF, Smith BL, Sartor CI, Leung EH, Abrams J, Schilsky RL, Muss HB, Norton L: Randomized trial of dose-dense versus conventionally scheduled and sequential versus concurrent combination chemotherapy as postoperative adjuvant treatment of node-positive primary breast cancer: first report of intergroup trial c9741/cancer and leukemia group b trial 9741. J Clin Oncol 2003; 21:1431-1439.

16 Regan MM, Pagani O, Walley B, Torrisi R, Perez EA, Francis P, Fleming GF, Price KN, Thurlimann B, Maibach R, Castiglione-Gertsch M, Coates AS, Goldhirsch A, Gelber RD: Premenopausal endocrine-responsive early breast cancer: Who receives chemotherapy? Ann Oncol 2008;19:1231-1241.

17 Batist G, Ramakrishnan G, Rao CS, Chandrasekharan A, Gutheil J, Guthrie T, Shah P, Khojasteh A, Nair MK, Hoelzer K, Tkaczuk K, Park YC, Lee LW: Reduced cardiotoxicity and preserved antitumor efficacy of liposome-encapsulated doxorubicin and cyclophosphamide compared with conventional doxorubicin and cyclophosphamide in a randomized, multicenter trial of metastatic breast cancer. J Clin Oncol 2001;19:1444-1454.

18 Lorusso V, Manzione L, Silvestris N: Role of liposomal anthracyclines in breast cancer. Ann Oncol 2007;18 Suppl 6:vi70-73.

19 Romond EH, Perez EA, Bryant J, Suman VJ, Geyer CE, Jr., Davidson NE, Tan-Chiu E, Martino S, Paik S, Kaufman PA, Swain SM, Pisansky TM, Fehrenbacher L, Kutteh LA, Vogel VG, Visscher DW, Yothers G, Jenkins RB, Brown AM, Dakhil SR, Mamounas EP, Lingle WL, Klein PM, Ingle JN, Wolmark N: Trastuzumab plus adjuvant chemotherapy for operable her2-positive breast cancer. $\mathrm{N}$ Engl J Med 2005;353:1673-1684.

20 Piccart-Gebhart MJ, Procter M, Leyland-Jones B, Goldhirsch A, Untch M, Smith I, Gianni L, Baselga J, Bell R, Jackisch C, Cameron D, Dowsett M, Barrios CH, Steger G, Huang CS, Andersson M, Inbar M, Lichinitser M, Lang I, Nitz U, Iwata H, Thomssen C, Lohrisch C, Suter TM, Ruschoff J, Suto T, Greatorex V, Ward C, Straehle C, McFadden E, Dolci MS, Gelber RD: Trastuzumab after adjuvant chemotherapy in HER2-positive breast cancer. N Engl J Med 2005;353:1659-1672.

21 Modi S, D'Andrea G, Norton L, Yao TJ, Caravelli J, Rosen PP, Hudis C, Seidman AD: A phase I study of cetuximab/paclitaxel in patients with advanced-stage breast cancer. Clin Breast Cancer 2006;7:270-277.

22 Chabner BA, Roberts TG, Jr.: Timeline: chemotherapy and the war on cancer. Nat Rev Cancer 2005; 5:65-72.

23 Giordano SH, Buzdar AU, Smith TL, Kau SW, Yang Y, Hortobagyi GN: Is breast cancer survival improving? Cancer 2004;100:44-52.

24 Wilking N, Jönsson B: A pan-European comparison regarding patient access to cancer drugs. 2005.

25 Peppercorn JM, Weeks JC, Cook EF, Joffe S: Comparison of outcomes in cancer patients treated within and outside clinical trials: Conceptual framework and structured review. Lancet 2004;363:263-270.

26 Kummar S, Kinders R, Rubinstein L, Parchment RE, Murgo AJ, Collins J, Pickeral O, Low J, Steinberg SM, Gutierrez M, Yang S, Helman L, Wiltrout $\mathrm{R}$, Tomaszewski JE, Doroshow JH: Compressing drug development timelines in oncology using phase ' 0 ' trials. Nat Rev Cancer 2007;7:131-139.

27 Kamb A: What's wrong with our cancer models? Nat Rev Drug Discov 2005;4:161-165.
28 Kummar S, Doroshow JH, Tomaszewski JE, Calvert AH, Lobbezoo M, Giaccone G: Phase 0 clinical trials: Recommendations from the task force on methodology for the development of innovative cancer therapies. Eur J Cancer 2009;45:741-746.

29 Greil R: The still long and winding road to neoadjuvant systemic therapy as the standard of care in breast cancer. Breast Care 2006;1:352-357.

30 Tan AR, Swain SM: Therapeutic strategies for triplenegative breast cancer. Cancer J 2008;14:343-351.

31 Frasci G, Comella P, Rinaldo M, Iodice G, Di Bonito M, D'Aiuto M, Petrillo A, Lastoria S, Siani C, Comella G, D'Aiuto G: Preoperative weekly cisplatin-epirubicin-paclitaxel with g-csf support in triple-negative large operable breast cancer. Ann Oncol 2009

32 Nurgalieva Z, Xia R, Liu CC, Burau K, Hardy D, Du XL: Risk of chemotherapy-induced peripheral neuropathy in large population-based cohorts of elderly patients with breast, ovarian, and lung cancer. Am J Ther 2009

33 Jones M, Schenkel B, Just J, Fallowfield L: Epoetin alfa improves quality of life in patients with cancer: Results of metaanalysis. Cancer 2004;101:1720-1732.

34 Jenkins VA, Ambroisine LM, Atkins L, Cuzick J, Howell A, Fallowfield LJ: Effects of anastrozole on cognitive performance in postmenopausal women: A randomised, double-blind chemoprevention trial (ibis ii). Lancet Oncol 2008;9:953-961.

35 Bender CM, Sereika SM, Brufsky AM, Ryan CM, Vogel VG, Rastogi P, Cohen SM, Casillo FE, Berga SL: Memory impairments with adjuvant anastrozole versus tamoxifen in women with early-stage breast cancer. Menopause 2007;14:995-998.

36 Ahles TA, Saykin AJ: Candidate mechanisms for chemotherapy-induced cognitive changes. Nat Rev Cancer 2007;7:192-201.

37 Correa DD, Ahles TA: Neurocognitive changes in cancer survivors. Cancer J 2008;14:396-400.

38 Feldman DR, Baum MS, Ginsberg MS, Hassoun H, Flombaum CD, Velasco S, Fischer P, Ronnen E, Ishill N, Patil S, Motzer RJ: Phase I trial of bevacizumab plus escalated doses of sunitinib in patients with metastatic renal cell carcinoma. J Clin Oncol 2009; 27:1432-1439.

39 During MJ, Cao L: VEGF, a mediator of the effect of experience on hippocampal neurogenesis. Curr Alzheimer Res 2006;3:29-33.

40 Bohlius J, Schmidlin K, Brillant C, Schwarzer G, Trelle S, Seidenfeld J, Zwahlen M, Clarke M, Weingart O, Kluge S, Piper M, Rades D, Steensma DP, Djulbegovic B, Fey MF, Ray-Coquard I, Machtay M, Moebus V, Thomas G, Untch M, Schumacher M, Egger M, Engert A: Recombinant human erythropoiesis-stimulating agents and mortality in patients with cancer: A meta-analysis of randomised trials. Lancet 2009;373:1532-1542.

41 Wilke RA, Lin DW, Roden DM, Watkins PB, Flockhart D, Zineh I, Giacomini KM, Krauss RM: Identifying genetic risk factors for serious adverse drug reactions: Current progress and challenges. Nat Rev Drug Discov 2007;6:904-916. 